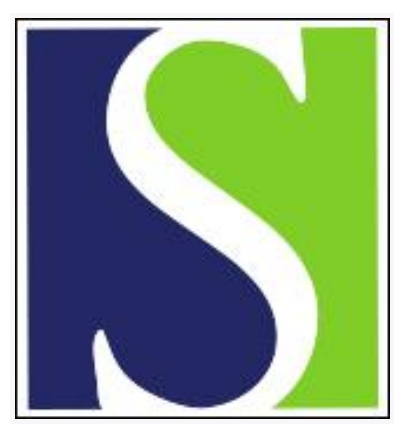

Scand J Work Environ Health 1979;5(2):151-157

https://doi.org/10.5271/sjweh.2657

Issue date: Jun 1979

Determination of inorganic fiber density in human lung tissue by scanning electron microscopy after low temperature ashing. by Gylseth B, Ophus EM, Mowé G

The following article refers to this text: 1979;5(3):290-296

Key terms: asbestos; ashing; human lung tissue; inorganic fiber density; low temperature ashing; lung tissue; scanning electron microscopy

This article in PubMed: www.ncbi.nlm.nih.gov/pubmed/472686 


\title{
Determination of inorganic fiber density in human lung tissue by scanning electron microscopy after low temperature ashing
}

\author{
by BJØRN GYLSETH, M.Sc., ${ }^{1}$ EGIL M. OPHUS, M.Sc., ${ }^{2}$ \\ and GUNNAR MOWÉ, M.D. ${ }^{1}$
}

\begin{abstract}
GYLSETH, B., OPHUS, E.M. and MOWE, G. Determination of inorganic fiber density in human lung tissue by scanning electron microscopy after low temperature ashing. Scand. j. work environ. \& health 5 (1979) 151-157. The concentration of asbestos fibers in lung tissue may give information about previous occupational asbestos exposure. A procedure for the preparation, quantification and identification of asbestos fibers in human tissue is presented in this report. The procedure is based on low-temperature plasma ashing of dry tissue, examination of the ash by scanning electron microscopy, and energy dispersive $\mathrm{X}$-ray microanalysis. The advantages and disadvantages of this method are also discussed briefly.
\end{abstract}

Key words: asbestos, lung tissue, scanning electron microscopy.

In 1929 Gloyne (8) demonstrated the occurrence of asbestos bodies and naked asbestos fibers in human 'Iung tissue of occupationally exposed persons. Some authors have tried to establish a relationship between asbestos lung-burden and specific lung diseases $(3,9,21)$, and it has been concluded that a definite dose-response relationship could occur. In earlier studies light microscopic techniques were used to demonstrate and quantify fibers in lung tissue. However, the optical resolution limit for asbestos fibers is estimated to be $0.5 \mu \mathrm{m}$. Most inorganic fibers found in lung tissue have

1 Institute of Occupational Health, Oslo, Norway.

2 Department of Biophysics, University of Trondheim, Trondheim, Norway.

Reprint requests to: Mr. B. Gylseth, Institute of Occupational Health, Box 8149, Dep, Oslo 1, Norway. a diameter far below this value and will most certainly not be detected with this technique.

More recently several authors $(2,12,17$, 19) have demonstrated that electron beam instruments can be used to identify and quantify inorganic particles; especially instruments equipped with a selected area electron diffraction (SAED) attachment and an energy dispersive X-ray spectrometer (EDS) are powerful analytical tools.

Dry ashing seems to be the most convenient and reliable method for decomposing tissue. Temperatures exceeding 400 $-450^{\circ} \mathrm{C}$ affect chrysotile asbestos by liberating water. Furthermore some volatile trace metals may be lost. Low-temperature plasma ashing seems to be the most convenient method with which to avoid these problems.

In this paper we report the use of a lowtemperature plasma asher and a scanning 
electron microscope (SEM) fitted with an energy dispersive $\mathrm{X}$-ray microanalyzer for the identification and quantification of mineral fibers in tissue from nonexposed and occupationally exposed persons.

\section{MATERIAL AND METHODS}

Samples of lung tissue were obtained during a postmortem examination of persons with a known cause of death. These persons included both nonexposed and occupationally exposed workers. Other samples were obtained from embedded autopsy material.

The stored material was embedded in paraffin wax, which was removed by means of cutting, melting and dissolving in xylene. Wet tissue $(0.4-1.5 \mathrm{~g})$ was curt and dried for $48 \mathrm{~h}$ at $80^{\circ} \mathrm{C}$. Tissue sections of this size had a reasonable number of fibers and not too much other material, which could cover the fibers on the filter area used in the investigation. After this procedure the dried tissue was ashed in a low-temperature plasma asher at temperatures below $200 \mathrm{C}$ (Tracerlab model LTA 505). Depending on the mass of dried tissue, a complete ashing was obtained after $2-4$ h.

The method was compared to wet digestion with $5 \%$ sodium hypochlorite (commercial bleach) using lung tissue from rats. Digestion of rat lungs in sodium hypochlorite gave an ash residue of $0.30 \%$ of the wet weight. Low temperature ashing gave $6.0 \%$ ash of dry weight and $1.2 \%$ of wet weight. Most of this ash consisted of slightly soluble alkali and alkaline chlorides, carbonates and phosphates. The ash was washed with $0.1 \mathrm{~N}$ hydrochloric acid, and after this treatment the residue constituted $0.24 \%$ of the wet weight. These data are consistent with those obtained by Jaunarajs and Liebling (10). The slightly higher ash residue from hypochlorite digestion may stem from undigested fat constituents. Fatty spots on the filter could be observed macroscopically.

After the low temperature ashing the residue of human lung tissue was 2.69 $\pm 0.45 \%$ of the dry tissue weight and 0.28

$\pm 0.06 \%$ of the wet tissue weight. After treatment with $0.1 \mathrm{~N}$ hydrochloric acid only $20-25 \%$ of the ash residue was left. This residue was dispersed by ultrasonics in water and filtered onto a $47-\mathrm{mm}$ Nuclepore filter with a pore size of 0.8 $\mu \mathrm{m}$. After drying, pieces of the filter were cut and mounted on carbon SEM stubs with carbon cement and coated with gold or carbon to make them conductive. The specimens were examined in a JEOL model JSM 35 SEM fitted with a PGT1000 energy-dispersive $\mathrm{X}$-ray spectrometer.

\section{RESULTS AND DISCUSSION}

The fiber concentration ranged from less than $1 \times 10^{4}$ fibers per gram of dry lung tissue from children to $66 \times 10^{6}$ fibers per gram of lung tissue from persons with known asbestos-related diseases. These values agree well with those found by other authors $(1,3,4,7,14)$. The numbers of fibers shown in table 1 were obtained from insulation workers with a complex occupational exposure. Sample a was taken from a person who died of pleural mesothelioma, b from a person who had suffered from pleural and lung fibrosis as well as bronchial cancer, and, finally, sample c fnom a person with a death diagnosis of bronchial cancer.

Fig. 1A-D shows typical naked fibers and asbestos bodies found in lung tissue from a mesothelioma patient. Lungs from insulation workers, who certainly have had severe asbestos exposure, often contain a large number of diatom fragments as well. This material stems from the insulation mass, which may be a mixture of asbestos and diatomaceous earth. These particles are identified by their characteristic morphological appearance, as well as their pure $\mathrm{Si}_{\mathrm{k} \alpha} \mathrm{X}$-ray spectrum. An electron micrograph of a diatom fragment is shown in fig. $1 \mathrm{E}$.

For the identification and quantification of particles found in human tissue, some experimental parameters have to be considered carefully. In the following 
discussion the main parameters will be presented and the results from the investigation reported.

\section{Magnification}

The samples were investigated with a random scanning across the membrane. Fiber number determination was made directly on the fluorescent screen in both the fast (TV) and the slow scanning mode. The magnification used for routine examination was $4,500 \times$. Fiber size evaluations were made at $4,500 \times$ (length) and $10,000 \times$ (diameter) magnification, respectively.

The choice of magnification was a compromise between resolution and the filter area evaluated. Two hundred "view fields" were counted for each specimen, each corresponding to a total area of $0.24 \mathrm{~mm}^{2}$. The fiber number varied from 10 to 200 for the $0.24-\mathrm{mm}^{2}$ areas examined. A higher fiber density on the filter is not recormmended since other materials may then cover the fibers. The thinnest fibers are certainly overlooked at a magnification of $4,500 \times$. However, if the optimal magnification $(10,000 \times)$ were to be used, the analysis would be extremely time-consuming due to the large number of fields which must be surveyed to get a significant number of fibers, and the method would no longer be recommendable as a screening procedure. The relation between the magnification and the number of fibers detected is shown in fig. 2 for two samples with different fiber densities per unit area. The sample with the highest fiber density was taken from the patient who died of mesothelioma, while the other came from the patient who died of bronchial cancer.

\section{Filtration}

Due to the plane surface and the welldefined pore size, Nuclepore membranes are superior to other filter types for this purpose. Filters with a $47-\mathrm{mm}$ diameter and a pore size of $0.8 \mu \mathrm{m}$ were used. We found that $0.8 \mu \mathrm{m}$ filters gave a better image for fiber counting than $0.2 \mu \mathrm{m}$ membranes. This difference might be due to the thinnest fibers being easier to detect when they cross the pores of the membrane. But using $0.8 \mu \mathrm{m}$ instead of 0.2 $\mu \mathrm{m}$ might produce a risk of losing short fibers. The retention of fibers was investigated with the use of subpleural tissue samples from a person with definite occupational asbestos exposure. Two adjacent tissue samples were ashed and transferred to $0.2 \mu \mathrm{m}$ and $0.8 \mu \mathrm{m}$ filters, respectively. By number analyses, no statistically significant difference could be observed between the number of fibers on the two filter types. However, the distribution in fig. 3 indicates that fibers shorter than $3 \mu \mathrm{m}$ might be lost during filtration onto $0.8 \mu \mathrm{m}$ Nuclepore membranes. Some fibers may be lost if they enter the filter surface in the "vertical" position. A fiber nearly lost is shown in fig. $1 \mathrm{~F}$.

In the SEM procedure the filters can be directly examined in the microscope. With transmission electron microscopy (TEM), however, significant losses may result from the complicated procedure of transferring the sample to the grids after digestion and filtration (6). On the other hand, the thinnest fibers are easier to detect in the TEM due to the higher resolution.

Many reports published in this field are based on the wet digestion of the tissue with concentrated alkali hydroxides, hydrogen peroxide, or sodium hypochlorite (commercial bleach) (10). The wet ashing techniques are time-consuming, and the risk of fiber loss is high. Concentrated solutions may attack the fibers and thereby affect the results. Furthermore, the liquids used may not completely ash the tissue, and some fatty residue may be left. This residue has to be removed either by washing with organic solvents or by centrifugation and decantation. It has been shown that fibers may be lost during the removal of the fat residue (I. R. Rüttner, personal communication).

\section{Identification criteria}

According to the theory of Stanton et al. (20), all fibers of a certain size may have a carcinogenic potential. Chrysotile and crocidolite asbestos have been shown to be the most cytotoxic fibers (5).

Also man-made mineral fibers are cytotoxic. Therefore all mineral particles with 


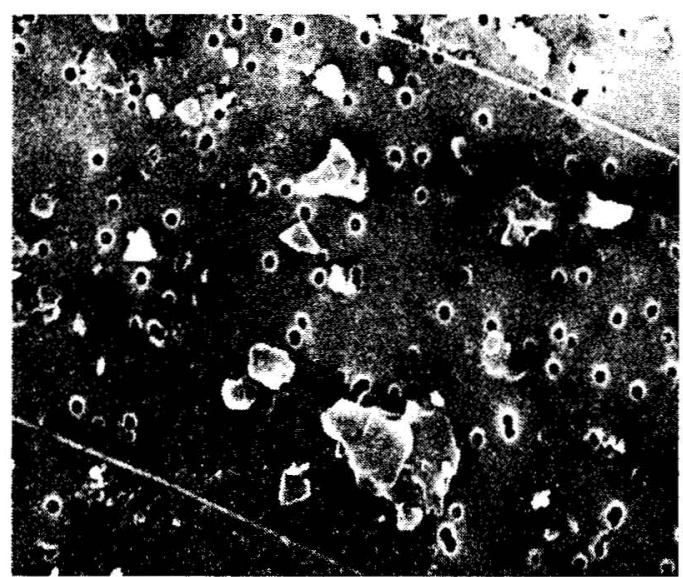

A $(6,000 \times)$

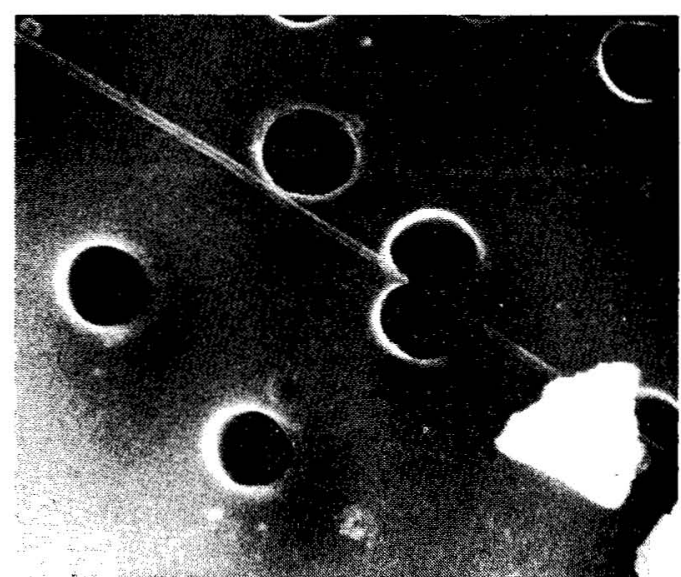

B $(10,000 x)$

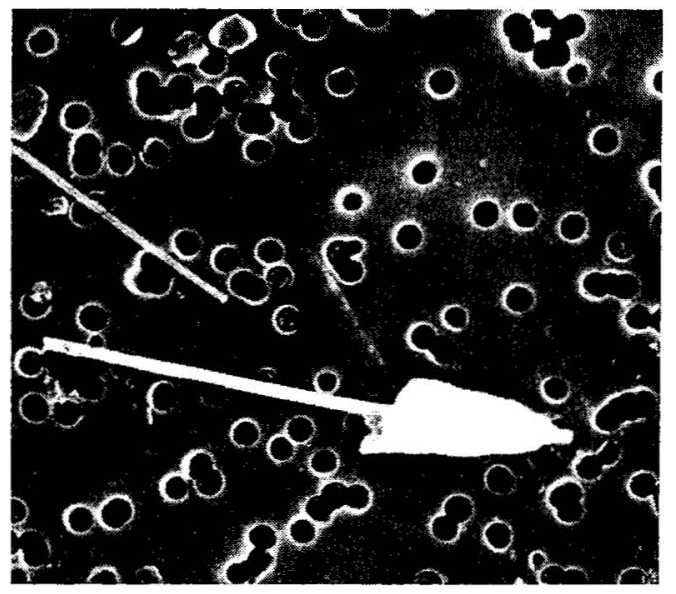

C $(3,200 \times)$

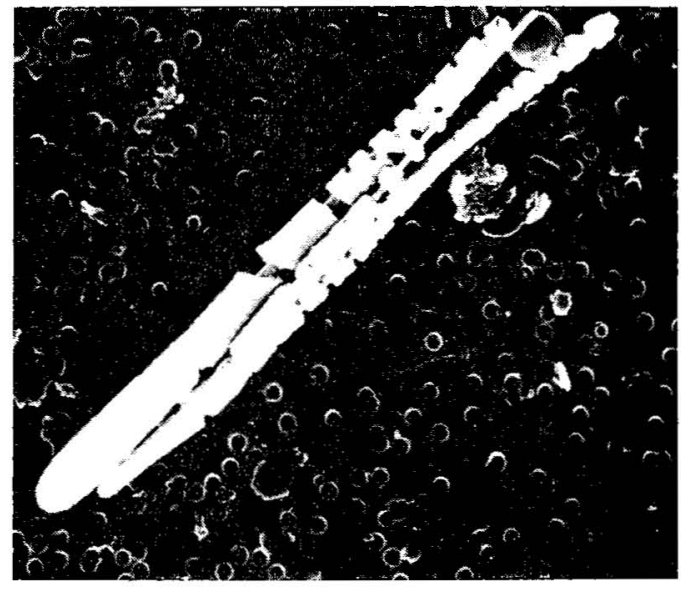

D $(2,000 \times)$

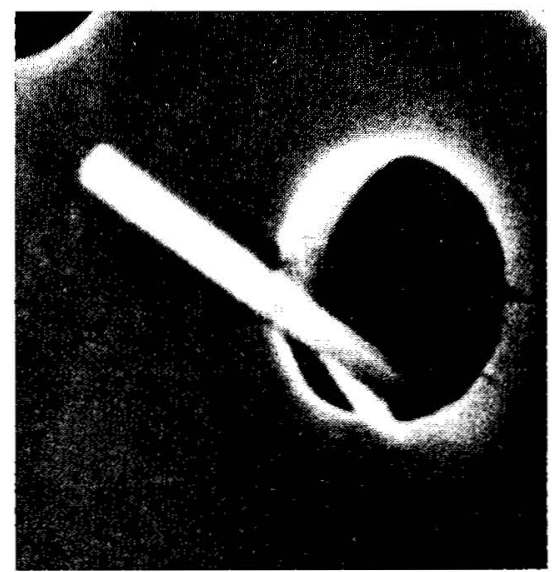

$F(30,000 \times)$
$E(10,000 \times)$

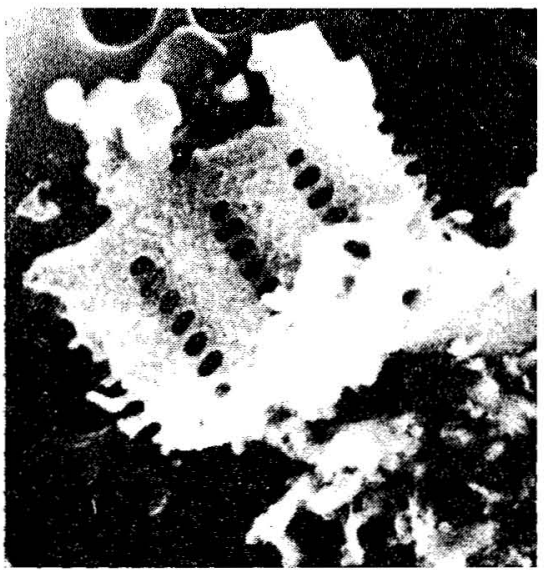




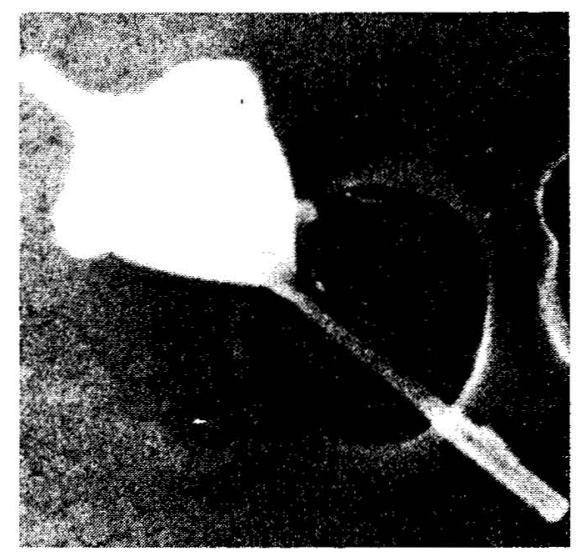

G $(30,000 \times)$
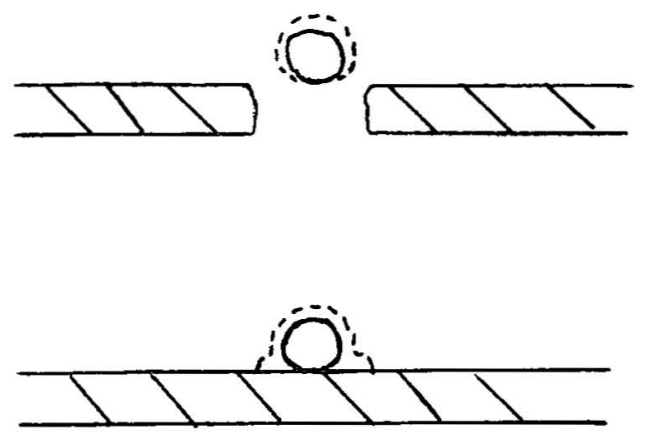

Fig. 1. $A, B, C$ and $D$ reveal uncoated and coated fibers of various sizes from an insulation worker who died of pleural mesothelioma; the morphological appearance, as well as the EDS spectrum, indicated asbestos fibers of the amphibole type; $C$ and $D$ show coated fibers with a different size of iron protein coating. $E$ shows a particle identified as a diatom fragment by morphology and the pure $\mathrm{Si}_{\mathrm{k} / 2} \mathrm{X}$-ray spectrum. $F$ shows a fiber nearly lost during the filtration procedure. $G$ and $H$ demonstrate the significance of the Au-layer; the sample was taken from the mesothelioma patient; $H$ shows a schematic drawing of a fiber crossing the membrane pore and laying on the plane filter, respectively.

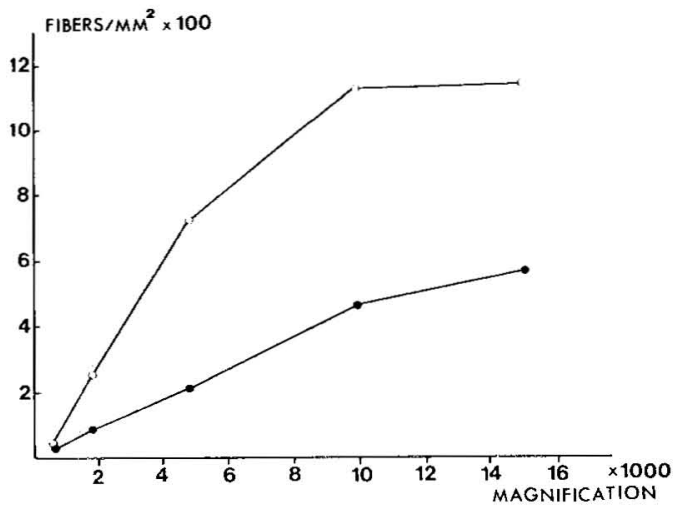

Fig. 2. Relation between number of fibers detected per unit area and the SEM magnification.

an aspect ratio greater than $3: 1$ are counted. In this study an energy dispersive X-ray microanalyzer was used to aid the identification of fibers. The fact that $\mathrm{Mg}^{2+}$ leaks from chrysatile in tissue both in vivo and in vitro makes it difficult to use this method for the identification of chrysotile $(11,13)$. The normal appearance of the

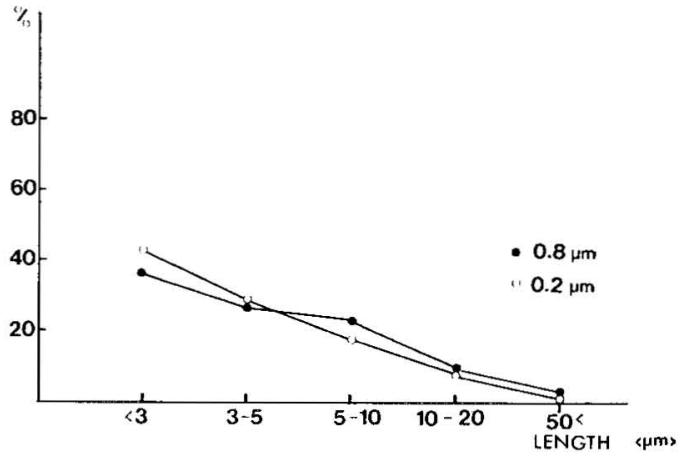

Fig. 3. Fiber length distribution at a magnilication of $4,500 \times$ in two adjacent tissue samples from the mesothelioma patient after low temperature ashing, treatment with hydrochloric acid and filtering. On $0.2-11 \mathrm{~m}$ membranes 554 fibers were evaluated. The corresponding number for $0.8-1 / \mathrm{m}$ membranes was 925 fibers.

typical long, silky chrysotile bundles seen in environmental and standard samples has not been detected in tissue samples. This lack may be due partly to the rapid 


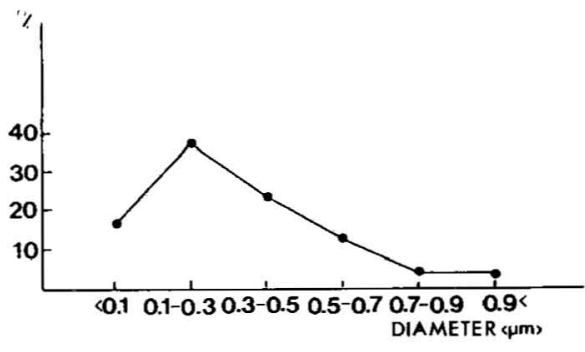

Fig. 4. Fiber diameter distribution of 110 random fibers in a tissue sample from the mesothelioma patient. The evaluation was made at $10,000 \times$.

Table 1. Variation of results after repeated counts by one and two persons, respectively.

\begin{tabular}{|c|c|c|c|c|}
\hline Sample & Examiner & $\begin{array}{l}\text { No. of } \\
\text { counts }\end{array}$ & $\begin{array}{c}\text { No. fibers/ } \\
\text { g dry } \\
\text { tissue }\end{array}$ & $+\mathrm{SD}$ \\
\hline$a$ & Person 1 & 4 & $36 \times 10^{6}$ & 2.8 \\
\hline $\mathrm{b}$ & $» 1$ & 4 & $9.6 \times 10^{6}$ & 0.6 \\
\hline $\mathrm{c}$ & $»$ & 4 & $9.5 \times 10^{6}$ & 0.9 \\
\hline c & 2 & 4 & $9.0 \times 10^{6}$ & 0.9 \\
\hline
\end{tabular}

pulmonary clearance of chrysotile and partly to the tendency of chrysotile to split into thin and short fibrils which can only be identified by the hollow central core seen in $\operatorname{TEM}(15,18,22)$ at very high magnification. The signal-tobackground ratio in EDS is poor for small particles $(<0.1 \mu \mathrm{m})$ due to the interaction of the electron beam and the substrate, and thus making the identification this way is still more difficult. After leakage of $\mathrm{Mg}^{2+}$ from chrysotile, these fibers might be recognized as anthophyllite. We have only classified fibers as chrysotile when the fiber spectrum consisted of $\mathrm{Mg}$ and $\mathrm{Si}$ peaks only and when these peaks approximated the intensities of chrysotile standards. In this study $90 \%$ of the fibers were classified as amphiboles (mostly crocidolite) through their EDS spectrum and the typical splitting into straight fibrils.

\section{Fiber-size determination}

The standard criterion used for the evaluation of asbestos fiber concentration in an environmental sample is the following: Fibers thinner than $3 \mu \mathrm{m}$, longer than 5 $\mu \mathrm{m}$ and with an aspect ratio greater than $3: 1$ are counted.

Most fibers found in lung tissue are thinner than $1 \mu \mathrm{m}$ and shorter than $10 \mu \mathrm{m}$, as shown in fig. 3 and 4 , respectively.

As to the size evaluation, one should be aware that the specimen is coated with a thin layer of gold ( $100-300$ A thick). An indication of the thickness of the gold coating is demonstrated in fig. 1G-H. The fiber core crossing the membrane pore is approximately $650 \mathrm{~A}$, while the part of the fiber resting on the membrane has a diameter of approximately 1,000 A (fig. 1G). This phenomenon is also illustrated by the schematic drawing in fig. $1 \mathrm{H}$. It certainly affects the classification of fiber diameters of less than $0.1 \mu \mathrm{m}$ and might result in a displaced diameter distribution.

\section{Fiber concentration}

In most papers the number of fibers in lung tissue samples are related to the weight of dry tissue. However, some authors relate fiber number to tissue volume $\left(\mathrm{cm}^{3}\right)$ (3) or to fiber weight (16). Especially, specification of fiber number per unit volume must be quite tedious, and the risk of introducing errors is high. Tissue including bronchioles and veins will be of different density than parenchymal tissue. Furthermore, the tissue investigated is often infiltrated with tumors, and fibrous and emphysematic tissue is of different density than normal tissue as well. Likewise, fiber-weight determinations are very tedious, since exact calibration against standards must be performed. Furthermore, a variety of fibers is found in most tissue samples, and this variation makes the calibration still more difficult and time-consuming. With these considerations as a basis, we recommend that results be presented as number of fibers per gram of dry tissue.

Potential inhomogenities in fiber distribution were investigated in an examination of pieces from three different parts of one membrane. No statistically significant differences could be observed. For these three samples we found $2.5,2.2$ and $2.5 \times$ $10^{7}$ fibers per gram of dry tissue, respec- 
tively. The variation in repeated counts on other samples is presented in table 1 . The standard deviation is satisfactory for these analyses. Besides, there is no statistically significant difference between repeated counts by two persons ( 1 and 2$)(p<$ 0.05 level).

Our study shows that scanning electron microscopy in combination with energy dispersive $\mathrm{X}$-ray microanalysis after a lowtemperature ashing procedure is suitable for identifying and quantifying inorganic, nonvolatile and acid-insoluble fibers in human lung itissue.

\section{REFERENCES}

1. ASHCROFT, T. and HEPPLESTON, A. G. The optical and electron microscopic determination of pulmonary asbestos fibre concentration and its relation to the human pathological reaction. J. clin. pathol. 26 (1973) 224-234.

2. BEAMAN, D. R. and FILE, D. M. Quantitative determination of asbestos fibre concentrations. Anal. chem. 48 (1976) 101110.

3. BIGNON, J., SEBASTIEN, P., FONDIMARE, A., BONNAUD, G., GAUDICHET, A., JANSON, $\mathrm{X}$. and MONCHAUX, G. Etude quantitative et qualitative des fibres d'amiante dans l'apparail respiratoire humain (Rapport de Institut de Recherche Universitaire sur l'Environment). Institut de Recherche Universitaire sur l'Environment, Paris 1978. 69 p.

4. BOUFFANT, L. Investigation and analysis of asbestos fibres and accompanying minerals in biological materials. Environ. health perspect. 9 (1974) 149-154.

5. CHAMBERLAIN, M. and BROWN, R. C. The cytotoxic effects of asbestos and other mineral dust in tissue culture cell lines. Br. j. exp. pathol. 59 (1978) 183-189.

6. CHATFIELD, E. J., GLASS, R. W. and DILLON, M. J. Preparation of water samples for asbestos fiber counting by electron microscopy. Ontario Research Foundation, Sheridan Park Research Community, Missisanga, Ontario 1977. $115 \mathrm{p}$.

7. FONDIMARE, A. and DESBORDES, J. Asbestos bodies and fibers in lung tissue. Environ. health perspect. 9 (1974) 147148.
8. GLOYNE, S. R. The presence of the asbestos fiber in the lesions of the asbestos workers. Tubercle 10 (1929) 404-407.

9. HEPPLESTON, A. G. Correlation between the tissue response and asbestos fibre content. Environ. health perspect. 9 (1974) $295-296$.

10. JAUNARAJS, K. I, and LIEBLING, R. S. The digestion of lung tissue for mineral dust recovery. Am. ind. hyg. assoc. j. 33 (1972) 535-542.

11. JAURAND, M. C., BIGNON, J., SEBASTIEN, P. and GONI, J. Leaching of chrysotile asbestos in human lungs: Correlation with in vitro studies using rabbit alveolar macrophages. Environ. res. 14 (1977) 245254.

12. LANGER, A. M., MACKLER, A. D. and POOLEY, F. D. Electron microscopial investigation of asbestos fibers. Environ. health perspect. 9 (1974) $63-80$.

13. LANGER, A. M., RUBIN, I. B. and SELIKOFF, I. J. Chemical characterization of asbestos body cores by electron microprobe analysis. J. histochem. cytochem. 20 (1972) $723-734$.

14. LANGER, A. M., SELIKOFF, I. J. and SASTRE, A. Chrysotile asbestos in the lungs of persons in New York City. Arch. environ. health 22 (1971) 348-361.

15. MASER, M. M., RICE, V. R. and KLUG, H. P. Chrysotile morphology. Am. mineral. 45 (1960) $680-688$.

16. POOLEY, F. D. Electron microscope characteristics of inhaled chrysotile asbestos fibre. $\mathrm{Br}$. $j$. ind. med. 29 (1972) 146153.

17. POOLEY, F. D. The identification of asbestos dust with an electron microscope microprobe analyzer. Ann. occup. hyg. 18 (1975) 181-186.

18. POOLEY, F. D. Turkish mesothelioma and Zeolites. Presented at the International Conference on Health Hazards of Asbestos Exposure, New York, NY 1978.

19. RUBIN, I. B. and MAGGIORE, C. J. Elemental analysis of asbestos fibers by means of electron probe techniques. Environ. health perspect. 9 (1974) 81-94.

20. STANTON, M. F., LAYARD, M., TEGERIS, A., MILLER, E., MAY, M. and KENT, E. Carcinogenicity of fibrous glass: Pleural response in the rat in relation to fiber dimension. J. natl. cancer inst. 58 (1977) $587-603$

21. WHITWELL, F., SCOTT, J. and GRIMSHAW, M. Relationship between occupations and asbestos-fibre content of the lungs in patients with pleural mesothelioma, lung cancer and other diseases. Thorax 32 (1977) $377-386$.

22. YADA, K. Study of chrysotile asbestos by a high resolution electron microscope. Acta crystallogr. 23 (1967) 704-707. 